\title{
SOCIOLOGIA DA GOVERNANÇA FRANCESA DAS ÁGUAS*
}

\author{
Rodrigo Constante Martins
}

\section{Introdução}

No início do século XX, ao descrever a constituição do que chamou de espirito capitalista, Max Weber destacava que a moderna ordem econômica determinaria "de maneira violenta o estilo de vida de todo nascido sob este sistema, e não apenas daqueles diretamente atingidos pela aquisição econômica, e, quem sabe, o determinará até que a última tonelada de combustível tiver sido gasta"

* Este artigo é parte do trabalho de pós-doutorado realizado pelo autor na École des Hautes Études en Sciences Sociales, em Paris, de dezembro de 2005 a agosto de 2006, com financiamento do Programme Hermès da Maison des Sciences de l'Homme (MSHParis). Agradeço a leitura atenta dos pareceristas anônimos da RBCS, cujas sugestões permitiram o aprimoramento da versão final do texto.

Artigo recebido em janeiro/ 2007

Aprovado em abril/2008
(Weber, 2000, p. 131). Sem embargo, o apontamento sobre a relevância da dimensão econômica na orientação das práticas sociais modernas feito pelo autor, bem como sua associação com o consumo extremo dos recursos naturais, adquire significado particularmente interessante no caso do moderno debate sobre a gestão das águas.

A temática do acesso aos recursos hídricos conquistou grande abrangência científica e política no decorrer das últimas três décadas. Publicações, conferências científicas sobre o tema e encontros multilaterais envolvendo técnicos e chefes de governo revelam a consolidação da questão hídrica na agenda política internacional. Do ponto de vista simbólico, também têm sido recorrentes as iniciativas de resignificação do recurso, associado, no mais das vezes, à importância mercantil que lhe foi conferida nas últimas décadas do século XX. Classificada por muitos como ouro azul ou mesmo petróleo do século XXI, a água segue ganhando abrangência na agenda 
política contemporânea, precisamente por sua importância estratégica para a produção econômica.

Essa re-significação do recurso também repercute na construção de novas estruturas de gestão social, voltadas fundamentalmente para o ideal econômico da alocação eficiente dos fatores de produção. Nesse sentido, em termos de práticas gestoras, a adoção dos chamados instrumentos econômicos vem sendo apontada como solução eficaz para o ajustamento do consumo social da água. Tais instrumentos teriam o mérito maior de refletir, por meio de mecanismos de preços, os níveis de escassez relativa do recurso, induzindo os agentes econômicos a adotarem condutas racionais de uso desse recurso, que seria então um capital natural.

Tanto no concernente à implementação de instrumentos econômicos de gestão das águas como em relação à criação dos Comitês de Bacias Hidrográficas como instâncias de governança do recurso, o caso francês é considerado uma importante referência internacional. No Brasil, o sistema paulista de gestão de águas, criado em 1991, e o Sistema Nacional de Gerenciamento de Recursos Hídricos, de 1997, tiveram como principal referência a experiência francesa de gestão. Os principais méritos atribuídos a tal experiência dizem respeito ao seu caráter descentralizado e ao seu modelo técnico. Ademais, no que se refere aos instrumentos de gestão, é comum nos debates sobre políticas ambientais e mesmo na literatura sobre gestão ambiental o destaque para a orientação do Princípio do Poluidor Pagador no instrumento francês de cobrança pelo uso da água (redevances). ${ }^{1}$

Inscrito no campo da temática "sociedade e recursos hídricos", este trabalho pretende contextualizar a abrangência do modelo francês de governança das águas a partir de sua interpretação sociológica. ${ }^{2}$ Ou seja, para além da imediaticidade dos instrumentos e das técnicas de gestão, pretende-se compreender interpretativamente a constituição dessa experiência francesa, resgatando seus principais agentes, a participação dos grupos profissionais na formulação do sistema gestor, a identificação dos distintos interesses envolvidos e a reconstrução dos principais termos do debate sobre as águas no país na década de 1960, período de criação das inovações institucionais de governança do recurso. Isto é, buscar-se-á compreender os elementos essenciais envolvidos na configuração que possibilitou a emergência do referido sistema gestor. Esse esforço interpretativo revela-se importante por pelo menos duas razões. Primeiro, pode contribuir, no plano das ciências sociais, para a crítica de Fabiani (1985, 1989), recorrendo a Habermas (1973), sobre o processo de "cientificização" da política, que se estrutura fundamentalmente na retórica do gerenciamento técnico dos conflitos socioambientais. Além disso, tal esforço pode revelar ainda que a reificação da retórica do gerenciamento científico dos recursos naturais também supõe a composição de interesses sociais que recorrentemente articulam grupos da ciência e da burocracia de Estado.

Este artigo está dividido em quatro seções. $\mathrm{Na}$ primeira são apresentadas as características gerais da governança francesa das águas, com destaque para seus principais instrumentos e instituições gestoras. Também são destacados os marcos conceituais que nortearão a interpretação sociológica do processo de construção do sistema gestor. $\mathrm{Na}$ segunda seção são iniciadas as interpretações sobre a configuração de agentes, grupos e instituições que propiciou a constituição desse sistema. Neste âmbito, buscar-se-á a interpretação do conteúdo do sistema, com ênfase no perfil dos agentes sociais partícipes de sua formulação. $\mathrm{Na}$ terceira seção são abordados alguns temas esclarecedores de como, para além de um simples modelo gestor, essa experiência francesa se constituiu em uma nova concepção social dos recursos hídricos, que culminou, conforme será abordado na quarta seção, em uma nova problemática das águas, baseada sobremaneira nas relações que destacam a dimensão econômica do uso do recurso. Por fim, nas considerações finais serão reafirmados os principais termos das discussões empreendidas no curso do texto.

Convém destacar que este trabalho não se propõe a analisar o caso específico de um comitê de bacia francês, explorando a formação de redes de representação social nestas esferas de gestão das águas. Propõe-se a interpretar as disputas sociais envolvidas no período de formação das normas gerais deste sistema gestor - disputas estas que conduziram à construção das possibilidades de trânsito dos agentes e dos grupos sociais no sistema. Com efeito, espera-se que a interpretação desta experiência de construção das bases do sistema permita, para os estudiosos da temática sociedade e recursos hidricos, um diálogo profícuo com o caso brasileiro, sobretudo porque este sistema se encontra, em vários estados, ainda em fase de gestação. 


\section{A forma francesa de gestão das águas: características gerais}

$\mathrm{Na}$ França, a gestão integrada dos recursos hídricos sustentada pela autoridade do poder central teve início no século XIX, com o Código Civil de 1804 . Até 1964 - ano que marca a criação legislativa do atual modelo gestor - a administração do recurso era tratada por diferentes serviços ministeriais, que abrangiam a economia e as finanças, a organização do território, a agricultura e a alimentação, a indústria e a energia, os serviços de navegação, os serviços de bem-estar social e as atividades de organização da pesquisa científica. A atuação de cada uma das instâncias ministeriais comportava objetivos específicos, relativos às prioridades setoriais e aos interesses dos distintos grupos da burocracia estatal (Haghe, 1998).

De acordo com Cheret (1987) e Picard (1987), agentes diretamente envolvidos na estruturação do novo aparato gestor, a reforma de 1964 pretendeu, dentre outros, transformar a dinâmica de administração do recurso, reforçando progressivamente a participação de distintos setores sociais nas novas instâncias gestoras. Entretanto, o processo de formulação da nova dinâmica administrativa caracterizou-se pela ausência de participação de grupos sociais que não aqueles já ligados à então tecnocracia envolvida na gestão do recurso. Ou seja, naquele período histórico - década de 1960 - a questão hídrica ainda não se constituía no interior da sociedade francesa como tema de disputas capazes de transformar aspirações setoriais em pautas políticas relevantes. Por essa razão, longe do espaço público, no sentido consolidado por Habermas (2000), ${ }^{3}$ a reforma de 1964 foi fundamentalmente o resultado da composição dos interesses e das interpretações da tecnocracia já envolvida com a administração das águas.

Como resultado desta ausência de publicização do conteúdo das reformas, a atuação dos formuladores do novo sistema gestor junto às autoridades legislativas francesas da época deu-se com base na legitimidade técnica da fala-perito destes agentes. $\mathrm{O}$ diálogo com setores da sociedade civil - caracterizados por Cheret (1987) como absolutamente vago no período - restringia-se à promessa de descentralização da gestão, com a participação futura dos usuários interessados. Em face do modelo centralizado então em vigor, tal promessa, sustentada não pelas autoridades governamentais, mas pelo grupo técnico reunido para planejar o novo aparato gestor, significava um importante avanço sobretudo para os agentes econômicos em ascensão no pós-1945. Neste contexto, como reitera Picard (1987), mesmo a expectativa da criação das redevances não despertou resistências imediatas, posto que as receitas delas provenientes seriam administradas (e porque não, também disputadas) nos contextos regionais. ${ }^{4}$

Para o processo de reforma, já em 1959 havia sido criada a Comissão da Água no âmbito do Comissariado Geral do IV Plano Econômico e Social francês. Seu papel era construir, no corpo do Estado, uma visão integrada da questão hídrica, visando a compor uma síntese das necessidades dos diferentes setores e assegurar a coerência geral dos investimentos previstos no quadro do planejamento nacional. Essa Comissão da Água também teve como missão a elaboração de um novo projeto de gestão das águas, que se constituiu na lei de águas de 16 de dezembro de 1964.

Com a lei de 1964, a coordenação administrativa do sistema foi estabelecida por meio da criação do Comitê Nacional de Águas, dos Comitês de Bacias e das Agências Financeiras de Bacia, sendo estes dois últimos responsáveis pela gestão em nível local. Os Comitês de Bacia seriam compostos pela representação paritária da administração central, das coletividades locais e de diferentes categorias de usuários. A rigor, esses comitês assumiriam no curso do tempo o status de pequeno parlamento das águas, cuja função primordial seria a arbitragem dos conflitos no uso e no acesso à água, tendo por base os termos da nova legislação nacional sobre o domínio do recurso e os esforços para combater sua poluição (Gleizes, 1987).

As Agências de Bacia, por sua vez, possuiriam um papel técnico na realização das metas estabelecidas pelos Comitês de Bacia. Seriam compostas de corpos técnicos e de um conselho de administração, com metade dos membros indicada pelo governo central e metade eleita pelo Comitê de Bacia. As Agências teriam como função realizar estudos qualitativos e quantitativos relativos aos recursos hídricos, centralizando os estudos e os programas de intervenção na escala da bacia. Contudo, seu papel central seria de ordem financeira, posto que estavam habilitadas por lei para a definição dos valores e para a cobrança das redevances. Elemento 
central do novo aparato gestor, as redevances constituir-se-iam em um valor monetário cobrado dos usuários de água que refletiria tanto a escassez relativa do recurso como os custos da degradação gerada privadamente.

Pouco mais de quarenta anos após sua criação, a atual estrutura francesa de governança das águas ocupa posição de destaque no debate internacional sobre modelos de gestão dos recursos naturais. Agências multilaterais destacam os méritos da experiência francesa, sobretudo no que se refere ao envolvimento de distintos grupos sociais na definição das formas de regulação do acesso e uso da água (OCDE, 2003; Dinar, 2000). Destacam também a pertinência do enfoque fisiográfico da gestão, baseada na noção de bacia hidrográfica (Saleth e Dinar, 1999). A literatura especializada no tema da gestão ambiental, por sua vez, sublinha que grande parte das virtudes do aparato francês de governança das águas deve-se às suas referências aos fundamentos que anos mais tarde se constituiriam no chamado Princípio do Poluidor Pagador da OCDE (Organização para a Cooperação e o Desenvolvimento Econômico). Como é sabido, tal princípio norteou, desde meados dos anos de 1970 , a formulação dos instrumentos de valoração econômica da água, tal como sugerido pelos autores da chamada economia ambiental (Valiron, 1990; Merret, 1997).

Contudo, o enfoque fisiográfico do sistema francês garantiria per si a certificação estritamente técnica atribuída a essa experiência gestora? Além disso, estariam de fato em discussão no caso francês as iniciativas próprias do Princípio do Poluidor Pagador? O significado das redevances corresponderia efetivamente às pressuposições teóricas da noção de valoração econômica da água presentes na economia ambiental? Senão, quais seriam as origens da crença, que envolve a literatura especializada em gestão ambiental e mesmo os movimentos ambientalistas, de que o recorte fisiográfico e as redevances indicariam um novo patamar de equilíbrio na gestão do uso e do acesso aos recursos hídricos?

A fim de indicar caminhos para as repostas de tais questões, desenvolveremos neste trabalho uma interpretação da configuração de agentes, grupos e instituições envolvidos na formulação dos marcos regulatórios do referido sistema gestor. Para tanto, empregaremos a noção de configuração proposta por Elias (1991, 1993). Para o autor, uma configuração estrutura-se como um jogo no interior do qual existe a hierarquia de conjuntos de relações do tipo "eu-eles" ou "nós-eles". As interdependências caracterizariam não apenas as relações entre agentes e ou grupos de agentes, mas também as relações entre níveis configuracionais. Isso porque as configurações com alto nível de organização são compostas freqüentemente de unidades parciais que formam, por seu turno, configurações localizadas e não menos estruturadas. Ou seja, as configurações localizadas são dispostas sobre vários planos, apresentando em cada caso um equilíbrio específico de forças. Nelas os indivíduos engajados ocupam posições identificáveis, mantendo laços de interdependência no plano configuracional. Esses cenários localizados representariam, nos termos do autor, "configurações no interior de configurações, processos no interior de processos, que podem consistir em múltiplos planos embricados, apresentando também, comparado uns aos outros, uma diversidade de forças e de capacidade de controle" (Elias, 1993, p. 44).

A reconstrução da configuração sobre a qual se construiu o atual modelo francês de gestão das águas será feita com base em informações sobre a composição das Comissões de Água dos Planos Econômicos e Sociais da França no período de criação da nova legislação das águas no país. Dentre outros, buscar-se-á identificar os perfis de formação dos membros dessas comissões (com destaque para a escolaridade e a origem de formação). A partir de tal identificação, lançaremos mão das concepções de Bourdieu (1989) sobre os quadros sociais de percepção de grupos e classes distintas, bem como de suas análises sobre as relações das Grandes Escolas francesas e o campo do poder. Também serão reconstituídos, com base em informações documentais do período, os termos gerais do debate sobre o devir do novo sistema gestor. Esses termos serão, por fim, confrontados com as avaliações posteriores feitas pelos formuladores do sistema em relação ao seu desenvolvimento no curso do tempo.

\section{O conteúdo do novo sistema gestor: grupos e configurações}

Em estudo sobre o perfil da gestão integrada das águas na França, Lewis (2001) reconstruiu a 
composição das Comissões de Água criadas nos quadros do quarto, do quinto e do sexto Plano Econômico e Social, desenrolados entre os anos de 1962 e 1975. Tal reconstrução revela, por exemplo, que na Comissão de Água do IV Plano Econômico e Social (1962 a 1965) 86\% dos membros eram politécnicos, portadores de diplomas da École Polytechnique $(53 \%)$, da École National de Ponts et Chaussées (30\%) e da École de Mines (14\%). No contexto da Comissão de Água do V Plano (1966 a 1970) - ou seja, período imediatamente posterior à criação da nova lei das águas -, o percentual de politécnicos cai para 51\%, destes, $56 \%$ são portadores de diplomas da École Polytechnique, 12\%, diplomados da École National de Ponts et Chaussées e os demais têm diplomas de variadas escolas politécnicas (com destaque, além da École de Mines, também para a École National du Genie Rural, a École Superieur d'Electricité, o Institut National Agronomique, a École du Petróleo de Strasbourg e o Institut Electrotechnique de Toulouse). Por fim, no VI Plano Econômico e Social (1962 a 1965), pouco mais de 40\% dos membros da Comissão de Água eram politécnicos, mantendo-se nessa fase o mesmo perfil de distribuição dos diplomas verificado no contexto do V Plano.

A diminuição relativa do número de politécnicos ao longo do período de formulação e implementação da lei francesa das águas de 1964 foi acompanhada pelo crescimento da participação de membros diplomados nas áreas de direito, letras e geografia. Conforme nos mostra Lewis (2001), nesses casos, a concentração dos diplomas revelou-se mais fraca que aquela verificada na formação dos politécnicos, sobretudo no curso do IV Plano Econômico e Social. As instituições com maior recorrência na concessão desses diplomas foram a Facultés des Lettres de Dijon, a Facultés des Lettres de Strasbourg, a Faculté des Lettres de Paris e a Faculté des Sciences et Droit de Paris.

Se partirmos desse cenário geral descrito por Lewis e avançarmos para a análise do perfil da direção das Comissões de Água do quarto, do quinto e do sexto Plano Econômico e Social, a relevância do perfil dos diplomas para a construção de um novo olhar administrativo sobre a gestão das águas na França torna-se ainda mais evidente. A direção da Comissão de Água do IV Plano, por exemplo, era constituída por um presidente, diplomado na Faculté de Droit de Strasbourg, e quatro vice-pre- sidentes, sendo três politécnicos, dois dos quais diplomados na École Polytechnique. A composição da direção da Comissão de Água do quinto e do sexto Plano Econômico e Social revela, ainda, maior concentração de poder nas mãos dos politécnicos, detentores então de todas as vice-presidências das respectivas comissões.

A despeito do discurso em relação à pluralidade de olhares sobre a gestão de águas que o novo sistema pressupunha, por meio da descentralização administrativa e da participação de usuários e distintos setores da sociedade civil nos Comitês de Bacia e nas Agências de Bacia, a participação efetiva dos grupos sociais nas referidas instâncias de governança possuía limites preestabelecidos. Esses limites referiam-se ao próprio quadro do sistema gestor, desenhado em grande medida pelos politécnicos. Isso porque a atuação desse grupo de profissionais na elaboração das novas normas de regulação de uso e acesso à água também acarretou a criação de novos marcos para a questão hídrica no país. Com efeito, as inovações jurídicas envolvem formas de nominação de experiências e expectativas sociais. Essas nominações, ao fornecerem balizas para o comportamento social, implicam também relações de poder. Nesses termos, desde a definição dos objetivos do novo aparato gestor até a regulamentação dos instrumentos da política de águas, conjuntos distintos de hierarquias sustentaram a nominação da atual problemática da água na sociedade francesa.

Nesse conjunto de hierarquias, uma das mais relevantes diz respeito ao que poderíamos chamar de dominação territorial dos saberes politécnicos. Primeiro diretor da Agência de Bacia Seine-Normandie, politécnico diplomado pela École Polytechnique e pela École National de Ponts et Chaussées e professor honorário desta última, Valiron (1987) destaca, em seu balanço dos primeiros vinte anos da criação das Agências de Bacia, a forma como os especialistas politécnicos disputaram a divisão do território em bacias hidrográficas. Segundo esse importante agente do novo sistema de gestão, ao contrário do que às vezes se supõe, a divisão do território francês em seis bacias hidrográficas não resultou de uma decisão eminentemente técnica, com base em recortes de bacias perfeitas ou grupos de bacias delimitados por critérios estritamente fisiográficos. A rigor, havia essa intenção inicial por parte dos membros das Comissões de Água, 
dividindo o território com base nos cursos dos grandes rios nacionais (Seine, Garonne, Loire e Rhône, sendo este último dividido em sua parte baixa, na costa do Mediterrâneo) e da cisão dos rios parcialmente franceses. Essa divisão corresponderia à criação de oito bacias hidrográficas. Contudo, as disputas dos três corpos de politécnicos no interior das comissões - a saber, os corpos de engenharia de minas, de engenharia de pontes e de engenharia rural - conduziram a decisão sobre a partilha do território em bacias hidrográficas para o campo do equilíbrio relativo das forças profissionais envolvidas. De acordo com Valiron, em razão dessas disputas, o território que inicialmente seria repartido em oito bacias hidrográficas foi dividido em seis bacias, sendo equilibradamente distribuído entre os três corpos politécnicos - cada um assumindo a direção de duas Agências de Bacia. Nos termos de Valiron:

O Secretariado Permanente tinha trabalhado um pouco na direção de oito Agências. E depois viu que havia um grande problema: quem ia assumir a direção das Agências? Como havia três corpos técnicos que brigavam para ter seus profissionais em cada uma das Agências, e não sendo neste caso 8 um número igualmente divisível, achou-se por bem chegar a um recorte de 6. E o recorte foi feito desta maneira! (1987, p. 132).

Segundo Levy-Lambert (1987), engenheiro de minas e também um dos participantes à época do debate sobre a partilha territorial, a atribuição da direção das Agências de Bacias baseou-se no equilíbrio numérico destacado por Valiron e nos campos de interesse de cada grupo. Nesse sentido, o corpo de engenharia de minas assumiu a direção das Agências de Bacias do norte e do leste, regiões mais industrializadas e com maior diversidade de recursos minerais; o corpo de engenheiros de pontes assumiu as agências do Seine e do Rhône em razão de sua importância para a navegação e da localização das grandes cidades; e o corpo de engenharia rural, por sua vez, assumiu as agências das zonas agrícolas de Loire e de Garonne.

Na condição de referência internacional, principalmente em razão da adoção da bacia hidrográfica como unidade de planejamento e gestão, o modelo francês tem recebido reiteradamente leituras abstratas quanto ao seu significado efetivo em termos de políticas públicas. O sentido dessa abstração reside justamente nas iniciativas de interpre- tação de seu desenvolvimento exclusivamente baseadas em suas características técnicas mais evidentes. ${ }^{5}$ Abstraída do conjunto de relações de poder que lhe conferem sentido concreto, a gestão francesa por bacias emerge como solução técnica aplicada à necessidade de planejamento e uso sustentável das águas. E, desse modo, continua sendo apresentada como solução eminentemente técnica para a gestão racional das águas. Essa forma aparente do modelo de gestão contribui para a disseminação de um processo denominado por Habermas (1973) "cientifização da política", por meio do qual são difundidas na sociedade representações "científicas" da natureza e de suas modalidades de uso social. A regulação do acesso aos recursos naturais, por meio dos instrumentos de gestão, é então consagrada como gerência científica da natureza. A política, prevista para o comitê de bacia (parlamento das águas), teria, portanto, um espaço prévia e cientificamente demarcado para a sua realização, a saber, a própria bacia hidrográfica. ${ }^{6}$

Essa modalidade de cientifização do processo político, ao abstrair as relações de poder envolvidas no recorte das bacias hidrográficas, o que o torna uma fórmula aparentemente técnica, contribui sobremaneira para a reafirmação de certos monopólios de competências. Assim, amparados pela experiência técnica francesa, corpos politécnicos de outros países estruturam seus discursos em torno da gestão racional das águas com base na bacia hidrográfica como unidade física e na criação de bancos de informações técnicas de gerenciamento. ${ }^{7}$ Também amparado por tal experiência, o saber técnico da água reiterou sua identidade na relação "nós-eles", opondo-se aos segmentos não-técnicos cuja atuação deveria significar a democratização do aparato gestor. ${ }^{8}$

Ademais, também é notória a precedência das formas discursivas como estratégias de dominação no próprio momento da constituição da modalidade de gestão. Destarte, é pertinente considerar, no âmbito desse processo, a formação de um espaço gestor onde a denominação bacia bidrográfica se estruturou concreta e simbolicamente por meio de disputas discursivas entre técnicos e não-técnicos e entre as distintas especialidades técnicas, circunstância que revela a complexidade das mediações lingüísticas envolvidas na consolidação do monopólio das competências gestoras. Retomando Habermas (1997) no concernente à mediação 
lingüística das relações intersubjetivas, pode-se afirmar que, nesse processo, o agir comunicativo dos grupos e dos agentes no momento da publicização da "gestão por bacias" na França revela interações estratégicas sobre os modos de prevalência de formas de ação lingüística candidatas, naquele momento, a serem aceitas como enunciados legítimos das inovações gestoras. Ou seja, a noção de bacia hidrográfica serviu, sob tais circunstâncias históricas, menos como critério de delimitação física da unidade de gestão do que como estratégia de persuasão social por meio do discurso supostamente técnico e neutro.

Nesses termos, é possível apontar, ainda no sentido habermasiano, a sujeição de distintos paradigmas culturais (entendidos como reservas de conhecimento às quais os participantes na comunicação vão buscar suas interpretações), distantes do campo científico, à objetivação da resolução técnico-burocrática. Isto é, ao aparentar-se como eminentemente técnica, tal solução revela a real interdição do diálogo e da intersubjetividade através justamente do lhe sustenta - a saber, o suposto planejamento científico e racional do devir político.

Essas circunstâncias forçam a elaboração de novas interpretações da nominação da experiência francesa. Interpretações que superem, dentre outros, a leitura restrita da lei de águas de 1964, como resultado da progressão do conhecimento técnico sobre recursos hídricos e gestão ambiental - progressão que teria culminado na noção de bacia hidrográfica. A lei francesa de 1964 também é produto de uma configuração que envolveu grupos profissionais, coordenados por sua maioria politécnica, portadores de interesses distintos - interesses estes que se equilibraram a partir da disposição dos grupos ante o mapa político das bacias hidrográficas. ${ }^{9}$ Ou seja, o próprio sistema de bacias hidrográficas também resulta de hierarquias sociais, de disputas políticas travadas no interior dos grupos profissionais e das burocracias responsáveis pela elaboração de um novo quadro de gerência das águas no país.

Além dessa disposição dos interesses sociais na divisão geográfica do novo sistema, outra hierarquia relevante para a interpretação das atuais formas de nominação da problemática da água na sociedade francesa diz respeito ao tipo de concepção hegemônica de relação sociedade-natureza que ampara os instrumentos de gestão. Essa interpreta- ção, contudo, requer o avanço sobre certos aspectos cognitivos envolvidos também na formação da identidade dos grupos profissionais que consolidaram as estratégias de dominação na nova configuração de governança das águas. Para tanto, torna-se pertinente a retomada do perfil de formação dos agentes formuladores da lei de 1964, além da própria disposição desses agentes no contexto das relações entre as chamadas Grandes Escolas Francesas e a burocracia de Estado no período.

A presença hegemônica dos politécnicos nas comissões de águas do quarto, do quinto e do sexto Plano Econômico e Social evidencia, em parte, o tipo de preocupação que a burocracia de Estado francesa possuía em relação à regulação do acesso e uso das águas no país. A rigor, a composição dessas comissões não revela alterações no perfil dos profissionais historicamente atrelados à gestão centralizada dos recursos hídricos. A preocupação principal na reestruturação do sistema dizia respeito a dois impasses intimamente imbricados: a crescente poluição dos corpos d'água e a necessidade de recursos financeiros para a recuperação das águas.

A descentralização da estrutura gestora e a criação das Agências Financeiras de Bacia foram as respostas produzidas, em configuração específica, por grupos profissionais que, dentre outros, partilhavam de concepções muito próximas não propriamente de gestão ambiental (campo técnico que viria a se desenvolver na década de 1980), mas de gestão pública. Tal proximidade não resultava do acaso. Sem embargo, o perfil de formação desses profissionais é uma variável relevante para a compreensão de uma visão relativamente coesa de gestão pública. Como destacado anteriormente, grande parte dos diplomas politécnicos dos membros das comissões de águas dos Planos Econômicos e Sociais era proveniente da École Polytechnique. Mesmo dentre os que possuíam formações mais específicas nas chamadas escolas de aplicação - como as também tradicionais École de Mines ou a École de Ponts et Chaussées -, a formação de base havia sido feita na Polytechnique.

Após sua criação, no início do século XIX, a École Polytechnique logo se tornou referência no sistema de ensino francês, tanto em razão das características de sua formação técnica e científica como pelo perfil dos egressos que a escola oferecia aos quadros do Estado. ${ }^{10}$ Conforme destaca Gilpin (1970), a despeito da ênfase no ensino científico 
proporcionada pela Polytechnique (ênfase, aliás, prevista já nos primeiros debates sobre a criação da escola, ocorridos em meados da década de 1790, durante a revolução), raros eram os egressos que se envolviam em atividades de pesquisa científica. Tal ênfase científica foi historicamente desenvolvida no ensino da escola, tendo em vista antes a aplicação prática das tecnologias do que propriamente a produção de novos conhecimentos. Assim, a escola consolidou-se no contexto do ensino francês como formadora não do engenheiro pesquisador, mas, sim, do engenheiro administrador, provido de conhecimentos científicos e de capacidade de planejamento e aplicação. ${ }^{11}$

Voltada para o cenário da administração pública, a École Polytechnique ocupou posições de destaque no campo do poder na sociedade francesa ao longo do século XX. Em seu estudo sobre a relação de homologia estrutural entre o campo das Grandes Escolas e o campo do poder na França, Bourdieu (1989) mostra como o diploma dessa escola constituiu-se em um rito de instituição não apenas para a reprodução das elites francesas, mas também para a composição do campo burocrático. ${ }^{12}$ Como demonstra o autor, no universo das escolas de engenheiros, as três escolas de maior prestígio, abrindo as três grandes carreiras - École Polytechnique, École de Mines e École de Ponts et Chaussées -, opõem-se às escolas mais técnicas, preparando os alunos aos setores e carreiras bem determinadas, comumente em declínio ou desvalorizadas. Assim, a organização do campo das instituições de ensino superior contribui para reproduzir uma das oposições maiores da ordem social, isto é, aquela que separa os quadros superiores dos quadros médios, os agentes encarregados da concepção (ordens, planos, programas, instruções) e os agentes encarregados da execução. Essa oposição corresponderia, no nível da divisão do trabalho, à oposição entre trabalho não-manual e trabalho manual, entre teoria e prática.

A presença dos politécnicos, diplomados na École Polytechnique, na École de Mines e na École de Ponts et Chaussées, nos quadros das Comissões de Água dos planos econômicos e sociais das décadas de 1960 e 1970 é uma expressão importante dessa homologia estrutural, sinalizada por Bourdieu, entre o campo das Grandes Escolas e a esfera do poder na França. O domínio desses diplomados sobre as funções de direção dessas comis- sões reitera tal relação. Focando a interpretação para a disputa interna entre as Grandes Escolas de engenharia, a divisão do território nacional em bacias hidrográficas revela, por sua vez, o equilíbrio flutuante de tensões entre tais forças institucionais na esfera do poder. A rigor, a divisão dessas unidades fisiográficas de gestão significou a partilha do território francês, ao menos no domínio das águas, entre os corpos das Grandes Escolas de aplicação. Ou seja, por meio da "cientifização" do processo político, sustentada neste caso pela suposta partilha técnica do território para fins de gestão ambiental, foram naturalizados não apenas os monopólios de competências sobre as águas, mas também os domínios que as instituições formadoras de espiritos para os corpos do Estado poderiam exercer sobre o espaço físico. Assim, a "cientifização" da política no sistema de gestão de águas atua como um princípio de legitimação de competências e de partilha do território, servindo, portanto, como fundamento de dominação social.

Evidentemente, essa relação das escolas de poder com o espaço físico por meio da gestão das águas não se sustentou apenas sobre a partilha dos territórios de atuação. Além disso, a produção de visões sobre a natureza, com base na concepção de gestão pública dos politécnicos, contribuiu sobremaneira para a formatação do sistema francês de gestão das águas. A seguir, abordaremos essa produção de visões sobre os recursos da natureza por meio da formulação das redevances, o instrumento decisivo de gestão dos Comitês e das Agências de Bacias francesas.

\section{A moderna construção social da água}

A interpretação dos quadros da percepção do mundo social - e, neste caso, da percepção e da construção da própria natureza - pode objetivar não somente os quadros sociais da percepção, mas também, como sugere Bourdieu (1989), o potencial de diferenciação que os distintos princípios de classificação possuem para construir o mundo social. Além de pressupor a influência do perfil de formação dos agentes do sistema de gestão das águas, tornase também pertinente a busca do limite crítico dessa influência. Ou seja, em termos de interpretação sociológica, é relevante tanto o apontamento do potencial de diferenciação de um princípio de clas- 
sificação, como seu limite, isto é, o ponto crítico a partir do qual o mesmo torna-se contraditório ou tem seu potencial de influência diluído. Nesses termos, considerando o perfil de formação dos politécnicos franceses como princípio de classificação na constituição da questão hídrica a partir da década de 1960, também serão discutidas as contradições que tal princípio traz ao próprio discurso de sustentabilidade ambiental que o atual modelo gestor enseja.

Componentes importantes da visão dos politécnicos formuladores da lei de 1964 sobre a administração dos recursos hídricos nacionais podem ser revelados a partir da interpretação do processo de formulação do principal instrumento de gestão do novo sistema, a saber, a redevance. Conforme já ressaltado, tal instrumento foi inicialmente concebido no caso francês como alternativa para a arrecadação dos recursos financeiros necessários às atividades de gestão. Contudo, os recursos discursivos tomados como legítimos para a implementação das redevances ao longo do tempo não se basearam nessa necessidade de captação financeira. Após a criação das redevances na ordem jurídica francesa, a retórica de validação que acompanhou sua implementação paulatina girou em torno da noção de penalização dos agentes poluidores. Esta noção, por sua vez, adquiriu nominação definitiva em 1972, por meio da proposição da OCDE do Princípio do Poluidor-Pagador (PPP).

A base conceitual sobre a qual se sustenta o PPP é o sistema lógico-dedutivo da economia ambiental neoclássica. Partindo das noções de equilíbrio e utilidade de Pareto (1983) e Walras (1983), bem como do conceito de externalidade de Pigou (1932), a economia ambiental propõe a incorporação do comportamento dos agentes econômicos poluidores na modelagem neoclássica de alocação eficiente dos recursos. Nesse modelo, a peculiaridade dos recursos naturais seria justamente seu caráter público, nãorival. Ao serem produzidas privadamente e gerarem custos sociais (isto é, ao afetarem as funções de utilidade de outras firmas e/ou consumidores), as externalidades resultantes das práticas individuais afetariam o bem-estar dos demais agentes econômicos e interfeririam no equilíbrio das relações de oferta e demanda dos recursos naturais. No diagnóstico da economia ambiental, a alternativa para o enfrentamento das práticas de poluição dos agentes econômicos seria justamente a incorporação das chamadas externalidades ambientais no cálculo das condutas individuais (Baumol e Oates, 1988). ${ }^{13}$

O PPP é justamente uma tentativa de promoção da internalização das externalidades ambientais por parte dos agentes poluidores. Contudo, considerando esses pressupostos conceituais, seria relevante indagar em que medida as noções ainda preliminares do poluidor-pagador basearam de fato a formulação da legislação francesa das águas de 1964, ou, ainda, até que ponto os integrantes das Comissões de Águas dos Planos Econômicos e Sociais do período tinham ciência das formulações em economia das noções de externalidades e de internalização das externalidades.

Embora nenhum dos membros das Comissões de Águas do período possuísse formação institucionalizada em economia na França, ${ }^{14}$ parte dos politécnicos envolvidos na criação das Agências de Bacias, sobretudo os da área de minas, seguia participando de freqüentes estágios de estudos em escolas de gerenciamento nos Estados Unidos (Barraqué, 1991). Tais estudos implicavam, dentre outros, o contato dos engenheiros com os pressupostos conceituais da microeconomia neoclássica. A freqüência desses estudos por parte dos engenheiros de minas deveu-se, particularmente, à criação, no início da década de 1950, da Communauté Européenne du Charbon e de l'Acier, que promoveu tanto a ida de politécnicos europeus aos Estados Unidos como a vinda ao continente europeu de missões norte-americanas (Braudel e Labrousse, 1980).

Todavia, esse acesso dos profissionais franceses às escolas norte-americanas não significou somente a incorporação das novas tecnologias de aplicação desenvolvidas no novo mundo. Como esclarece Boltanski, esse acesso também significou a assimilação, por certos quadros da sociedade francesa, de uma nova filosofia de gerenciamento econômico, que implicava novas modalidades de organização do trabalho industrial e valores renovados de planejamento econômico. Nos termos do autor, tratava-se de verdadeiras missões de produtividade, que envolviam um savoir-faire para além dos conhecimentos de engenharia; tratava-se de missões que visavam a "antes de tudo transformar o 'espírito', as maneiras de ser e pensar dos agentes econômicos" (Boltanski, 1981, p. 21).

Se, de um lado, essas inovações se referiam mais nitidamente ao universo da economia industrial, de outro, é impossível desconsiderar sua influência 
na formulação de certas políticas estatais de gestão. No caso das águas, uma das representações mais significativas é a noção de gestão racional. Tal como também destaca Boltanski (1981), a incorporação da noção de gestão racional da empresa pela sociedade francesa nesse período foi acompanhada da crença na organização científica da gerência como um todo. Não coincidentemente o planejamento da organização científica da gestão das águas pautar-se-ia em dados pluviométricos, informações sobre unidades geológicas, balanço hídrico, classificação dos corpos d'água etc. A ordem racional da gestão, por sua vez, partiria desde a organização dos dados técnicos até o enquadramento da racionalidade do usuário-poluidor por meio da aplicação das redevances.

Também nesse sentido é importante o destaque dado por Haghe (2005) para as mudanças na própria nominação do modo de administração das águas promovidas pelas inovações institucionais $\mathrm{da}$ lei de 1964. A expressão simbólica mais significativa dessas mudanças seria, como sugere o autor, a ruptura léxica no discurso técnico-administrativo por meio da substituição do termo aménagement (até então consolidado na administração francesa das águas) pelo termo gestion. Ou seja, substitui-se a concepção de esforço político de aprimoramento da partilha social dos recursos hídricos pela noção de gerência técnica, pretensamente distante das disputas políticas e resultante do planejamento racional. Tal mudança serviria, ainda, para a reafirmação dos discursos em prol do monopólio de competências, posto que a base informacional para as atividades de gestão, diferentemente do universo da política de planejamento, exigiria cada vez mais a especialização técnica dos agentes responsáveis.

Contudo, se alguns desses novos conhecimentos sobre técnicas de gerenciamento serviram de base conceitual para o novo sistema gestor, a implementação de seus pressupostos deu-se com base em formas específicas de conversão e reinterpretação. Mais especificamente, sua influência sobre o espirito dos novos gestores condicionou-se às preocupações que demandaram a renovação das formas de administração das águas no país. Nesse sentido, se, de um lado, os pressupostos da microeconomia sugeriam a transformação das práticas poluidoras por meio dos mecanismos de preços, de outro, o aspecto de maior interesse para os politécnicos das Comissões de Águas era justamente o planejamento da gestão em termos de equilíbrio entre receitas e despesas. Não é por outra razão que, tal como destaca Barraqué (1991), os instrumentos de planejamento aprendidos nas escolas norte-americanas de gerenciamento eram comumente pensados no âmbito dessas comissões não exclusivamente por meio dos casos empíricos das iniciativas de gestão econômica das águas nos Estados Unidos (com a criação, por exemplo, dos mercados de água), mas também - e principalmente por meio da experiência de cobrança pelo uso da água na bacia do rio Ruhr, na Alemanha.

Datada do início do século XX, a experiência de cobrança pelo uso e pela poluição das águas do rio Ruhr visava, em essência, à realização dos investimentos necessários à bacia e de outras atividades ligadas à gestão. Em 1913, a cobrança já atingia todos os segmentos sociais, e seus valores eram definidos com base no planejamento dos investimentos. Com efeito, foi justamente esse sentido prático da cobrança na experiência alemã a base por meio da qual as redevances francesas foram pensadas e implementadas. Ou seja, dentro do objetivo de enfrentar a situação crítica da poluição das águas no país, a iniciativa da cobrança esteve ligada menos à previsão do comportamento microeconômico dos agentes (tal como viria a supor posteriormente o PPP) do que à previsão orçamentária das atividades de gestão.

Uma estratégia para compreender o distanciamento das redevances de suas justificações conceituais de internalização das externalidades ambientais é a reconstituição de sua composição financeira ao longo do tempo. No âmbito do sistema gestor, o valor integral das redevances é composto de duas frações: a relativa ao valor da água e a referente à poluição praticada pelo usuário. Por meio de tal divisão, o usuário pagaria pelo valor da água em si, como capital natural, e pela poluição emitida em seu uso privado. A primeira fração da redevance corresponderia mais precisamente à valoração do nível de escassez relativa do recurso e a segunda, à aplicação do PPP como estímulo ao seu uso racional.

Todavia, a aplicação prática das redevances revela uma contradição central nos suportes teóricos do referido fracionamento. Isso porque, desde 1976, $\mathrm{o}$ valor da fração correspondente à aplicação do PPP é determinado previamente por lei, no âmbito do governo central. Ademais, o valor aprovado por lei é único, sendo aplicado a todas as bacias hidrográficas. Isso significa que, a despeito da lógica 
de internalização das externalidades ambientais previstas no PPP - que supõe, evidentemente, a distinção entre os comportamentos individuais dos poluidores -, a fração de poluição das redevances é partilhada entre os todos usuários de bacia, não havendo, portanto, correspondência alguma entre poluição privada e internalização dos custos da poluição. ${ }^{15}$

Após os primeiros vinte anos da criação das Agências de Bacia no país, esta característica eminentemente orçamentária das redevances era apontada pelos partícipes da formulação da lei de 1964 como o grande impasse do novo sistema gestor. Em publicação que marcou a referida data, muitos agentes desse processo reportaram-se a esse dilema das redevances, que, em última instância, desfiguraria o papel das próprias Agências de Bacia. A esse respeito, uma das avaliações mais incisivas foi feita por Yves Martin, engenheiro de minas e primeiro diretor da Agência de Bacia Artois-Picardie:

\begin{abstract}
Um dos resultados mais aguardados era obrigar todo o poluidor a se interrogar sobre a quantidade de poluição vertida e pesar a contribuição relativa de cada poluidor. [.. .] Mas hoje, nós assistimos cada vez mais a um caminhamento das redevances para o âmbito das receitas caracteristicamente fiscais. Eu sinto muito em observar finalmente um grande desejo de transformá-la em uma redevance uniforme, cobrada por metro cúbico utilizado. Isto seria, a meus olhos, absolutamente desastroso, porque a redevance perderia seu aspecto modulado em função dos efeitos reais das atividades do usuário sobre o meio natural (Martin, 1987, p. 103).
\end{abstract}

Se o planejamento orçamentário foi o componente mais relevante para a decisão em favor das redevanes por parte dos formuladores do novo sistema de gestão de águas, a retórica de legitimação da cobrança no curso do tempo foi progressivamente associada ao ajustamento dos comportamentos individuais dos usuários de águas - aproximando-se, assim, dos pressupostos neoclássicos da alocação eficiente dos recursos. Posteriormente, as orientações de estímulo ao uso racional dos recursos naturais presentes na formulação do PPP contribuíram para sua associação às redevances e, ainda mais, para a associação destas últimas aos instrumentos neoclássicos de gestão ambiental. Essas associações foram decisivas, no plano cognitivo, não apenas para a justificação das redevances na sociedade francesa, mas também para sua repercussão internacional como instrumento-modelo de gestão ambiental.

\section{A economia da água como crença social}

Considerando a não-aplicabilidade empírica dos princípios econômicos que legitimam a existência das redevances como instrumento de racionalização do uso da água, faz-se necessário o exame da crença de seus fundamentos não-aplicados e reiteradamente sustentados por grupos sociais envolvidos na gestão descentralizada e mesmo por movimentos ambientalistas. Sem embargo, a noção de racionalização do uso da água vinculada aos instrumentos econômicos de gestão é, no momento presente, um elemento central nas representações sociais em torno da sustentabilidade ambiental.

Se a retórica em torno dos instrumentos econômicos de gestão ambiental encontra-se abrigada no seio do ambientalismo, seus fundamentos repousam não propriamente no campo do debate socioambiental. A rigor, a tarefa mais relevante da economia ambiental neoclássica no curso dos últimos trinta anos tem sido justamente disseminar em vários níveis de sociabilidade certas crenças a respeito do comportamento dos indivíduos em sociedade. Neste empreendimento, as representações do neoclassicismo em torno da racionalidade do bomo oeconomicus serviram de base à produção de uma leitura da relação sociedade-natureza que, embora específica, encontrou suportes em agentes e instituições para se disseminar como realidade objetiva. Esses suportes relacionam-se, dentre outros, com o modo de legitimação social da ciência econômica e com as disposições estruturadas que a realidade proposta pela economia ambiental encontrou no contexto do moderno debate sobre regulação ambiental.

No concernente à legitimação social do saber produzido pela ciência econômica, é notório o espaço ocupado pelos enunciados neoclássicos no conjunto das explicações sobre a moderna economia de mercado. Essa hegemonia, contudo, expressa tanto as disputas internas à ciência econômica como aquelas relativas ao establishment científico em sentido lato. No caso das disputas internas, um elemento de destaque diz respeito à hierarquia das ciências modernas, com base em sua proximidade do modelo ideal das matemáticas puras. Ou seja, conforme sugere Caro (1983), a propósito da produção de conhecimento na ciência econômica entre duas modalidades de produção de um enunciado econômico, a mais competitiva é aquela com maior potencial 
de matematização. Nesse contexto, a concorrência interna à ciência econômica tem levado seus agentes à crescente formalização de seus enunciados em busca de maior legitimidade acadêmica. No caso da economia ambiental, essa formalização é a base de suas formulações mais significativas, envolvendo os enunciados de valoração ambiental. ${ }^{16}$

A legitimidade simbólica dos enunciados da economia ambiental no conjunto das ciências dedicadas aos estudos ambientais também se assenta em grande medida nesse processo de formalização. Ingressando no establishment científico, a economia ambiental participa da administração dos argumentos da moderna crise socioambiental, produzindo representações simbólicas ou reproduzindo representações herdadas. Nesse sentido, tal como afirma Elias (1982) sobre os monopólios do establishment científico, ao participar da administração dos argumentos e da produção de conhecimentos sobre as interações sociedade-natureza, a economia ambiental também monopoliza saberes determinantes para a orientação das práticas sociais.

No caso das disposições estruturadas que esses enunciados econômicos encontraram no âmbito do moderno debate sobre regulação ambiental, é importante destacar que configurações distintas de agentes e grupos sociais envolvidos na regulação do uso dos recursos naturais respondem por parte das características dos instrumentos econômicos de cada sistema gestor. Isto é, a despeito do espaço da ciência econômica e dos enunciados neoclássicos no establishment científico, a criação dos instrumentos econômicos de gestão também revela modos particulares de disputas políticas entre governos, burocracias de Estado e grupos organizados da sociedade civil. No caso francês, Lebaron (2000) destaca que a própria economia neoclássica se impôs no país como uma ciência de Estado: foi antes de tudo utilizada no quadro de uma economia em parte planificada, justificando, notadamente, tarifações dos serviços públicos. Nesse sentido, o autor também destaca que o neoclassicismo foi um importante instrumento para estratégias de modernização das disputas no campo burocrático da sociedade francesa.

Outra força do modelo neoclássico apontada por Lebaron (2000) - e aqui não apenas no caso francês - é a estreita correspondência entre a crença política e a crença burocrática, em que a definição de objetivos quantificáveis comanda a pesquisa de meios formais e econômicos para sua própria realização. É justamente nesse caso que se revela a fusão da crença gerencial e, mais especificamente, financeira, pela qual o ganho monetário funciona como uma meta, dando a toda ação sentidos subjetivo e objetivo particulares - tal como supõem os instrumentos de gestão baseados no PPP.

Ou seja, tal como assinala Bourdieu (2000), as teorias econômicas exercem efeitos objetivos sobre as práticas sociais. Assim, enunciados econômicos sobre gestão ambiental, ou a nominação econômica da questão ambiental, podem permitir a promoção de decisões multilaterais (envolvendo Estados nacionais e instituições de mediação) ou mesmo a formulação de políticas com repercussões imediatas sobre distintos grupos sociais. Os efeitos produzidos pelas teorias econômicas mais "puras" supõem a produção do illusio, com a existência de um círculo de crentes bem mais amplo do que o mundo dos profissionais da economia.

Desta feita, os instrumentos econômicos de gestão ambiental podem ser compreendidos como momento do processo de diferenciação e autonomização do próprio campo econômico. Do mesmo modo que nesse processo as transações econômicas deixaram de ser dominantemente concebidas/ explicadas como trocas domésticas, comandadas então por obrigações familiares ou sociais, dando lugar a um novo princípio de visão dominante voltado aos cálculos individuais de custo-benefício, as concepções sobre as modalidades de relação sociedade-natureza também acompanharam esse processo de conversão subjetiva e objetiva da realidade social. Desse modo, cabe a descrição de Bourdieu, em concordância com Max Weber, de que "a teoria da utilidade marginal é um fato histórico-cultural que manifesta este aspecto fundamental das sociedades contemporâneas que é a tendência à racionalização - formal -, notadamente correlata à generalização das trocas monetárias" (2000, p. 19).

Os instrumentos econômicos de gestão ambiental em geral e os de gestão das águas em particular adquirem nova complexidade analítica para as ciências sociais quando interpretados nesse contexto de disputas sobre a construção de visões sociais da realidade. Justamente porque são nessas disputas que os agentes sociais transitam em redes, em diferentes configurações e atuam efetivamente na construção das visões de mundo. No caso da experiência francesa sobre a nova problemática das 
águas, um dos casos exemplares em relação ao trânsito dos agentes em diferentes contextos configuracionais é o de Ivan Chéret, então secretário das Comissões de Água do IV, do V e do VI Plano Econômico e Social.

$\mathrm{Na}$ função de secretário permanente das comissões, de acordo com os próprios partícipes do processo, este reconhecido quadro de confiança do Ministério do Meio Ambiente à época conquistou grande prestígio entre especialistas e membros das recém-criadas Agências de Bacias em razão de seu envolvimento com as várias dimensões que a nova lei de águas pretendia se reportar. Posteriormente, o politécnico (diplomado da École Polytechnique) ainda desempenhou papel fundamental na continuidade dos debates travados nas três comissões ao longo dos dezesseis anos de maturação e implementação do novo sistema gestor. Tornouse, desde a década de 1980, um importante consultor do Banco Mundial para o tema da gestão das águas. Envolvido cada vez mais com os problemas da chamada nova economia da água, este agente vem participando, desde 2000, de grupos de trabalho sobre a questão hídrica junto à Organização das Nações Unidas. Dedica-se especialmente a interpretações dos desafios de gestão das águas para o milênio, em estreita parceria com Michel Camdessus, ex-diretor do Tesouro francês, ex-governador do Banque de France e ex-diretor geral do Fundo Monetário Internacional. Atual conselheiro para o tema da água da Secretaria Geral das Nações Unidas, Camdessus fundou em 2002 o "Grupo de trabalho mundial sobre o financiamento das infra-estruturas de água", do qual Cheret é desde então o secretário geral.

No ano de 2004, em parceria com outros três especialistas na questão hídrica, Camdessus e Cheret publicaram um livro no qual reúnem dados e interpretações sobre os dilemas de acesso à água, da poluição e das dificuldades institucionais de gestão do recurso em várias regiões do mundo (Camdessus et al., 2004). A obra desenvolve fundamentalmente a leitura econômica das possibilidades de escassez do recurso, atentando para a necessidade de sua alocação eficiente. O sentido do texto assemelha-se ao conteúdo corrente dos documentos de instituições como a OCDE e o Banco Mundial, voltados para uma forma retórica de neutralidade e pragmático no sentido das orientações tecnocráticas. ${ }^{17} \mathrm{Na}$ obra, os agentes engajam o capital simbó- lico adquirido individualmente para a construção de uma nova problemática da água, circunscritos em configurações institucionais de reconhecida legitimidade internacional. A retórica desenvolvida na publicação contribui, assim, para a partilha de uma visão da relação sociedade-recursos hídricos em configurações distintas. Atua na esfera da nominação do moderno desafio das águas, isto é, a argumentação concorre na luta simbólica pela nominação legítima dos objetos e das relações no mundo social.

\section{Considerações finais}

Este trabalho teve por objetivo principal uma interpretação sociológica da constituição da moderna experiência francesa de gestão das águas. Nesta tarefa, realizou-se o resgate da configuração de parte das disputas entre grupos e instituições envolvidos na elaboração e na implementação do referido sistema gestor. Para tanto, recorreu-se a uma estratégia de abordagem dedicada menos à descrição dos instrumentos de gestão do que à exposição da dinâmica dos interesses setoriais no quadro de formulação dos novos marcos regulatórios da governança das águas no país.

O mapa político das bacias hidrográficas revelou-se como importante fundamento de crítica à tese da partilha técnica do território para fins de gestão das águas. Conforme visto, as necessidades de conformação dos interesses dos grupos politécnicos no âmbito da gestão influíram decisivamente não apenas na divisão da gerência das bacias entre os grupos profissionais, mas também serviram de base à legitimidade entre os então agentes formuladores do marco regulatório para a definição do número de bacias a serem criadas. Nesse sentido, o que historicamente apresentou-se como produto estritamente técnico de uma modalidade de engenharia gestora - cujos maiores méritos residiriam justamente em sua neutralidade técnica -, tratou-se também de um processo de disputa entre grupos profissionais e segmentos da burocracia de Estado. Esse fundamento crítico possui particular relevância para a análise das iniciativas de "cientifização" da política como princípio de legitimação de competências e de partilha do território. No caso da governança francesa das águas, é mister destacar que a lei de 1964 não é o resultado da progressão do conhecimento técnico, que teria culminado com 
a noção de bacia hidrográfica, mas sim produto de uma configuração que envolveu agentes (sobretudo politécnicos) e instituições com interesses distintos, interesses estes que se equilibraram (no sentido do equilíbrio flutuante de tensões) a partir da disposição das Agências de Bacias. No que concerne à construção da identidade "nós-eles", as relações de oposição revelaram-se tanto em plano configuracional mais amplo, com a polarização entre o saber técni$\mathrm{co} /$ perito e os demais segmentos sociais dispostos a se envolver na governança descentralizada, como no interior da própria tecnocracia, com as identidades dos três principais corpos politécnicos.

Um elemento não tratado neste estudo, mas que requer ainda esforços analíticos, diz respeito ao caso particular dos comitês de bacia. Destarte, a análise da atuação das redes de representação social nestas instâncias, bem como suas relações com os quadros técnicos, não implicaria em um adicional a este artigo, mas sim em sua seqüência (tanto do ponto de vista histórico como analítico). Neste caso, caberia o emprego de certos instrumentos interpretativos utilizados nas abordagens sociológicas das práticas econômicas. Isto porque, atualmente, as relações entre as redes de representação e a tecnocracia vinculam-se em grande medida à aplicabilidade (ou não) dos princípios econômicos da valoração da água. Por certo, os comitês de bacia constituemse em espaços de disputas e, por conseguintes, de interações sociais características, enquadrando-se no que Steiner (1999), por exemplo, categoriza como rede social no escopo da sociologia econômica. $\mathrm{O}$ emprego de tal suporte analítico, supõe-se, pode contribuir para evidenciar a dificuldade de construção de um padrão de relações/interações entre esta tecnocracia e os grupos sociais, posto que, como bem demonstra o presente artigo, tendo a dominação social dos saberes politécnicos empreendido características muito peculiares aos destinos de cada bacia hidrográfica, as redes na representação social dos comitês de bacia devem também revelar características fortemente localizadas.

Por fim, é importante ainda destacar a eficácia ímpar da associação do modelo francês de gestão das águas a certas crenças econômicas. Tal como se procurou demonstrar, várias relações continuaram sendo implicadas na crença da auto-regulação promovida pela valoração dos recursos naturais, com destaque para sua forma institucional mais acabada, qual seja, a do Princípio do Poluidor-Pa- gador. A produção do illusio por meio dos enunciados econômicos da questão ambiental e do encontro desses enunciados com disposições estruturadas em agentes e instituições, que dele se apropriaram como crença, mostrou-se como importante caminho para o esclarecimento das estratégias que recursivamente encerram os temas da moderna crise socioambiental nos termos das análises de custo-benefício. A definição dos instrumentos de gestão ambiental como instrumentos econômicos revela, dentre outros, a leitura hegemônica que a tecnociência segue construindo sobre o ambiente natural e, em nível mais complexo, seu uso como instrumento de poder legítimo ante outros grupos sociais.

Dessas conclusões, emerge, portanto, a hipótese do que se pode desenhar como um mercado internacional de instrumentos de política ambiental, voltado para a gestão econômica dos recursos naturais. Os parlamentos das águas (gestão descentralizada) e a valoração ambiental (apoiada no PPP) são alguns dos bens com ampla circulação nesse mercado. Por certo, o caso francês oferece-nos aspectos decisivos sobre a gênese desses bens no contexto das políticas de águas. Cumpre, portanto, a realização de novos esforços analíticos para a compreensão da circulação internacional desse modelo, que segue como importante amparo, dentre outros, para a recente experiência brasileira de gestão descentralizada dos recursos hídricos.

\section{Notas}

1 No Brasil, a cobrança pelo uso da água encontra-se em fase de implementação. No estado de São Paulo, a proposta de cobrança foi aprovada como lei pela Assembléia Legislativa em dezembro de 2005. Sua implantação será realizada pelos Comitês de Bacias Hidrográficas. No plano federal, a cobrança também é prevista em lei e o Comitê Federal do Rio Paraíba do Sul vem praticando-a desde janeiro de 2006.

2 Convém esclarecer que o emprego do termo governança não se circunscreve ao campo da construção de valores corporativos, tal como comumente vem sendo aplicado nos estudos de economia e administração. A despeito da concordância com a suposição de Bourdieu (2000, pp. 22-23) quanto à visão moral específica revelada por certos modos de aplicação do termo, este trabalho explorará o referido termo com base no contexto por meio do qual o mesmo se circunscreveu no debate francês de gestão das águas. Nesse sentido, o termo gover- 
nança será aqui utilizado em face do debate sobre a descentralização da gestão socioambiental por meio da promoção do princípio da subsidiaridade. Nas discussões sobre gestão e políticas públicas, tal princípio supõe que toda a ação que pode ser decidida e implementada no âmbito da localidade não deve ser submetida à decisão de nível hierárquico superior, decorrendo daí uma divisão funcional em termos de arranjos institucionais e de envolvimento dos interesses sociais locais na construção de políticas no - e não para o - território. Para o detalhamento e a problematização deste princípio, ver Faure (1997). Para a relevância deste debate no campo da governança socioambiental, ver os estudos de caso de Howard (2006) e Boonstra (2006).

3 Em Habermas (2000), o espaço público é concebido como lugar onde as interpretações e as aspirações em questão se manifestam e adquirem consistência ante os distintos agentes e grupos sociais, interpenetrando-se, entrando em sinergia ou em conflito. Ressalta-se, assim, a importância da expressão pública das aspirações e dos processos de deliberação e/ou decisão.

4 Em termos de atuação articulada da sociedade civil, o único grupo a desenhar alguma reação quanto aos rumos do debate sobre o novo sistema gestor no início dos anos de 1960 foi formado pelas associações de pescadores de águas doces. Isto porque uma das primeiras versões do projeto de lei propunha a classificação dos cursos d'água em quatro categorias, em função de seu grau de poluição. Os pescadores, agentes pioneiros nas denúncias sobre a poluição nos rios do país, alegavam que tal categorização significava aceitar a idéia de que certos cursos d'água pudessem ser legalmente poluídos. Como solução para o impasse, foi mantido na lei um texto vago sobre a possibilidade de classificação dos rios, que seria eventualmente definida por decretos do Conselho de Estado.

5 A análise de Nicolazo (1997) é um importante exemplo da abstração da dimensão política na história da criação das agências de bacias francesas. A propósito da leitura do depoimento de Valiron sobre os vinte anos de criação das Agências de Bacia, este autor afirma que a relevância da experiência reside justamente na dimensão técnica norteadora do debate. O relato das disputas políticas não teria tanta importância vis à vis a relevância técnica adquirida pelas Agências de Bacia.

6 Este processo de "cientifização da política" no escopo do moderno debate sobre desenvolvimento sustentável possui vários campos de manifestação. Sua forma mais evidente talvez se refira à extensão do campo dos especialistas em gestão de territórios e ecossistemas até o exercício científico dos instrumentos de políticas públicas. A propósito das contradições desta modalidade de relação entre conhecimento científico e ação política no debate sobre regulação ambiental, ver Fabiani (1985).

7 Notadamente, este também é o caso brasileiro. Os manuais de gestão e gerenciamento dos recursos hídricos, elaborados pelos "profissionais" das águas no país, re- velam fortemente esta reafirmação do monopólio de competências.

8 Esta oposição tornou-se bastante evidente nas décadas seguintes à criação da referida lei, com a consolidação dos comitês de bacia. Estudos como os de Fritsch (1998), sobre a atuação política das empresas de distribuição de águas na França nos anos de 1980, e de Lewis (2001), sobre as disputas políticas na bacia Loire-Bretagne, revelam a fragilização da participação dos distintos setores sociais nos comitês justamente em razão do ornamento técnico do debate político. Ambos os estudos apontam para a recorrência a este ornamento por representantes governamentais e de grandes empresas nos momentos de maior impasse político dentro dos comitês - fato que sugere o sentido da formação de novas redes tendo o saber técnico como um dos capitais de sustentação.

9 A referência de equilíbrio aqui empregada baseia-se na definição de equilibrio flutuante de tensões de Elias (1991). $\mathrm{Na}$ perspectiva deste autor, tal definição implica a retomada da noção de poder em contexto relacional e circunscrito a configurações definidas. As possibilidades de equilíbrio das tensões flutuantes seriam, em termos analíticos, uma das particularidades estruturais de toda configuração.

10 Tal como destacou Walter Benjamin (2006) a propósito da consolidação de Paris como capital do século XIX, o conceito moderno de engenheiro na França, cujas origens remontam às guerras da revolução, começa a se impor cotidianamente por meio das rivalidades entre o construtor/planejador e o decorador - o que no espaço das grandes escolas correspondia à oposição entre a École Polytechnique e a École des Beaux-Arts, sendo esta última a base erudita dos segmentos burgueses atrelados ao comércio e à indústria têxtil. Nessas rivalidades, entrariam em questão os próprios valores sociais em torno das paisagens (sobretudo as urbanas), bem como aqueles envolvidos com o universo das técnicas.

11 Segundo Shinn (1980), esse perfil adequava-se perfeitamente ao próprio ideal nepoleônico de formação de profissionais polivalentes para o corpo do Estado. Nesse sentido, o recrutamento dos alunos na Polytechnique seguiu progressivamente representando, ao menos até o final da década de 1970, quase um recrutamento de Estado, de tal sorte que os egressos da escola contavam com a certeza da ocupação de posições nos quadros da administração pública.

12 Na perspectiva de Bourdieu (1989), os ritos de instituição assumiriam funções parecidas com aquelas dos ritos de nominação (batismo, circuncisão etc.). No caso das instituições de ensino superior, são atas de nominação oficiais do sistema escolar nos termos da demarcação do caminho percorrido. A apreciação desse caminho funda-se na lógica dualista do pertencimento e da exclusão, fornecendo identidades sociais e, por conseguinte, distinções, marcadores sociais das diferenças (no caso francês, seria o "normalien", o "polytechnicien" 
etc.). Nesse contexto, os índices de sucesso escolar não seriam levados em conta; a hierarquia dos indivíduos corresponderia mais estreitamente ao valor de mercado dos títulos do que ao valor propriamente escolar de seu desempenho.

13 Este trabalho não tem por objetivo desenvolver a crítica conceitual dos princípios neoclássicos para a questão ambiental. Para tal crítica, ver Godard (1980) e Leff (2003). Sobre a interpretação pormenorizada das estratégias conceituais de problematização da gestão das águas pelo neoclassicismo, ver Martins (2004).

14 Conforme destaca Lebaron (2000), a designação economista no país possui sentido polissêmico. Isso principalmente em decorrência da ausência, até os anos de 1970, de uma trajetória institucionalmente demarcada no sistema de formação profissional. Os primeiros departamentos de economia nas instituições de ensino e pesquisa do país datam do final da década de 1960, oferecendo formação aplicada principalmente aos diplomados das áreas politécnicas e de direito.

15 A propósito da internalização dos cursos de produção, Berger e Roques (2005) destacam o fato de os agricultores não pagarem a redevance de poluição. A despeito dos argumentos técnicos envolvidos nas características de emissão difusa de poluição agrícola, tem sido notória a atuação dos agricultores no sistema de governança a fim de garantir a não penalização do setor. Segundo os autores, este fato contribuiria para aquilo que denominam de opacidade na gestão francesa das águas.

16 A crescente formalização matemática das técnicas de valoração bem como as inovações nos modelos de precificação podem ser acompanhadas nos trabalhos de Pearce (1995) e Goldar e Misra (2001).

17 Este sentido geral de neutralidade nos enunciados também é marcante no próprio documento do Princípio do Poluidor Pagador da OCDE. A propósito desta modalidade de construção discursiva no campo econômico, bem como de sua eficácia simbólica, ver Lebaron (2000).

\section{BIBLIOGRAFIA}

BARRAQUÉ, B. (1991), Les politiques de l'eau en Europe. Paris, Éditions la Découverte.

(1997), "Subsidiarité et politique de l'eau", in Alain Fauré (org.), Territoires et subsidiarité: l'action publique locale à la lumière d'un principe controversé, Paris, L'Harmattan (col. Logiques Politiques).

BAUMOL, A. \& OATES, W. (1988), The theory of environmentalpolicy. 2 ed. Cambridge, Cambridge University Press.
BENJAMIN, W. (2006), Passagens. Belo Horizonte/São Paulo, Editora da UFMG/Imprensa Oficial do Estado de São Paulo.

BERGER, C. \& ROQUES, J. L. (2005), L'eau comme fait social: transparence et opacité dans la gestion locale de l'eau. Paris, L'Harmattan (col. Sociologie et Environnement).

BOLTANSKI, L. (1981), "America, America... Le Plan Marshall et l'importation du 'management". Actes de la Recherche en Sciences Sociales, 38, maio, p. 19-41.

BOONSTRA, W. J. (2006), "Policies in the Polder: how institutions mediate between norms and practices of rural governance". Sociologia $\mathrm{R} u$ ralis, 46 (4), out, p. 299-317.

BOURDIEU, P. (1989) La noblesse d'État: grandes écoles et esprit de corps. Paris, Les Éditons de Minuit.

(2000), Les structures sociales de l'économie. Paris, Seuil.

BRAUDEL, F. \& LABROUSSE, E. (1980), Histoire économique et sociale de la France. Paris, PUF, vol. 2.

CAMDESSUS, M. et al. (2004), Eau. Paris, Éditions Robert Laffont.

CARO, J. Y. (1983), Les économists distingués: logique sociale d'un champ scientifique. Paris, Presses de la Fondation Nationale des Sciences Politiques.

CHERET, I. (1968), "Le probleme de l'eau et les agences financieres de bassin”. Problèmes Economiques, n. 1068, 20 juin. Institut National de la Statistique e des Études Economiques.

. (1987), "Point de vue: la loi sur l'eau et les Agences de Bassin", in Hubert Loriferne (ed.), 40 ans de politique de l'eau en France, Paris, Ed. Économica.

DINAR, A. (2000), The political economy of water pricing reforms. Washington/Nova York, The World Bank/Oxford University Press.

ELIAS, N. (1982), "Scientific establishment", in Norbert Elias, Herminio Martins e WHITLEY, Richard Whitley (eds.), Scientific establishment, Londres, D. Reidel Publishing Company. 
(1991), Qu'est-ce que la sociologie?. Paris, Éditions de l'Aube.

(1993), Engagement et distanciation. Paris, Fayard.

FABIANI, J. L. (1985), "Science des écosystèmes et protection de la nature", in A. Cadoret (ed.), Protection de la nature: histoire e ideologie, Paris, Editions l'Harmattan, pp. 75-93.

(1989), "La nature, l'action publique et la regulation sociale", in N. Mathieu e M. Jollivet, Du rural à l'environnement: la question de la nature aujourd'bui, Paris, L'Harmattan.

FAURÉ, Alain. (1997), Territoires et subsidiarité: l'action publique locale à la lumière d'un principe controversé. Paris, L'Harmattan (col. Logiques Politiques).

FRITSCH, J. M. (1998) "Les ressources en eau: intérêts et limites d'une vision globale". Revue Française de Géoéconomie, 4: 93-103.

GILPIN, R. (1970), La science et l'État en France. Paris, Gallimard.

GLEIZES, M. (1987) 'La loi sur l'eau et sa mise en oeuvre", in Hubert Loriferne (ed.), 40 ans de politique de l'eau en France, Paris, Ed. Économica.

GODARD, O. (1980), Aspects institutionnels de la gestion intégrée des ressources naturelles et de l'environnement. Paris, Éditions de la Maison des Sciences de l'Homme.

GOLDAR, B. \& MISRA, S. (2001), "Valuation of environmental goods: correcting for bias in contingent valuation studies based on willingness-to-accept". American Journal of Agricultural Economics, 83 (1): 150-156.

HABERMAS, J. (1973), La technique et la science comme idéologie. Paris, Gallimard.

(1997), The theory of communicative action. Cambridge, Polity Press, vol. 1.

(2000), "La constellation post nationale et l'avenir de la démocratie". In HABERMAS, J. Après l'Etat-nation: une nouvelle constellation politique, Paris, Fayard.

HAGHE, J. P. (1998), Les eaux courantes et l'Etat en France 1789-1920: $\mathrm{d} u$ contrôle institutionnel à la fétichisation marchande. Tese de doutorado. $\mathrm{Pa}-$ ris, École des Hautes Études en Sciences Sociales.

(2005), "Les débuts de la merchandisation de l'eau en France au XIX siècle: enjeux et acteurs". Sciences de la Société, 64, fev, p.3545.

HOWARD, J. (2006), "Using game theory to explain the behaviour of participants involved in a regional governance process". Rural Society, 15 (3): 254-270.

LEBARON, F. (2000), La croyance economique: les économistes entre science et politique. Paris, Seul.

LEFF, E. (2003), "A geopolítica da biodiversidade e o desenvolvimento sustentável: economização do mundo, racionalidade ambiental e reapropriação social da natureza", in MARTINS, Rodrigo C. Martins e Norma F. Valencio (orgs.), Uso e gestão dos recursos hidricos no Brasil, vol. 2: Desafios teóricos e político-institucionais, São Carlos-SP, RiMa.

LEVY-LAMBERT, M. (1987), "Point de vue: la loi sur l'eau et les Agences de Bassin", in $\mathrm{Hu}-$ bert Loriferne (ed.), 40 ans de politique de l'eau en France, Paris, Ed. Économica.

LEWIS, N. (2001), La gestion intégrée de l'eau en France: critique sociologique à partir d'une étude de terrain. Tese de doutorado. Orléans, Université d'Orléans.

MARTIN, Y. (1987), "Point de vue: la loi sur l'eau et les Agences de Bassin", in Hubert Loriferne (ed.), 40 ans de politique de l'eau en France, $\mathrm{Pa}$ ris, Ed. Économica.

MARTINS, R. C. (2004), A construção social do valor econômico da água: estudo sociológico sobre agricultura, ruralidade e valoração ambiental no estado de São Paulo. Tese de doutorado. São Paulo, Universidade de São Paulo.

MERRET, S. (1997), Introduction to the economic of water resources: an international perspective. UCL Press Limited, Londres.

NICOLAZO, J. L. (1997), Les Agences de l'Eau. Paris, Pierre Johanet \& Fils Editeurs.

OCDE. (1992), The polluter-pays principle. Paris, Organisation de Coopération et de Développement Economiques, OCDE/GD, 81. 
. (2003) Améliorer la gestion de l'eau: l'experience récente de l'OCDE. Paris, Organisation de Coopération et de Développement Economiques.

PARETO, V. (1983), "Manual de economia política”. Os Economistas. São Paulo, Abril Cultural.

PEARCE, D. W. (1995), Blueprint 4: capturing global environmental value. Londres, Earthscan Publications Ltd.

PICARD, P. (1987), "Les problèmes qui ont conduit à la loi sur l'eau du 16 décembre 1964", in Hubert Loriferne (ed.), 40 ans de politique de l'eau en France, Paris, Ed. Économica.

PIGOU, A. (1932), The economics of welfare. 4 ed. Londres, Macmillan.

ROMI, R. (1994), Droit et administration de l'environnement. Paris, Montchrestien.

SALETH, R. M \& DINAR, A. (1999), Water challenge and institutional response. Policy Research Working Paper 2045, The World Bank Development Research Group Rural Development and Rural Development Department, January.

SHINN, T. (1980), L'École Polytechnique: savoir scientifique e powvoir social. Paris, Press de la Fondation Nationale des Sciences Politiques.

STEINER, P. (1999), La sociologie économique. Paris, La Découverte.

VALIRON, F. (1987), "Point de vue: la loi sur l'eau et les Agences de Bassin", in Hubert Loriferne (ed.), 40 ans de politique de l'eau en France, Paris, Ed. Économica.

. (1990), Gestion des eaux: principes, moyens et structures. Paris, Presses de l'École Nationale des Pontes et Chaussées.

WALRAS, L. (1983), "Compêndio dos elementos de economia política pura". Os Economistas, São Paulo, Abril Cultural.

WEBER, M. (2000) A ética protestante e o espirito do capitalismo. 15 ed. São Paulo, Pioneira. 


\section{SOCIOLOGIA DA GOVERNANÇA FRANCESA DAS ÁGUAS}

\section{Rodrigo Constante Martins}

Palavras-chave: Sociedade e recursos hídricos; Burocracia e gestão ambiental; Regulação ambiental; Gestão de águas.

A temática do acesso aos recursos hídricos conquistou grande abrangência científica e política no decorrer das últimas três décadas. A moderna experiência francesa tem se revelado como importante referência na institucionalização de novas práticas gestoras. No Brasil, esta experiência é a base não apenas da constituição dos novos aparatos gestores estaduais, mas também da própria formulação da Política Nacional de Recursos Hídricos. O objetivo deste artigo é apresentar uma interpretação sociológica sobre a construção do atual modelo francês de governança das águas. $\mathrm{O}$ autor busca reconstituir as disputas sociais mais relevantes envolvidas na tecnocracia de administração das águas no período de formulação do novo aparato gestor. Para tanto, será resgatada a trama sociopolítica que envolveu agentes, grupos e instituições sociais na definição do novo marco regulatório.

\section{SOCIOLOGY OF WATER GOVERNANCE IN FRANCE}

Rodrigo Constante Martins

Keywords: Society and water resources; Bureaucracy and environmental management; Environmental regulation; Water management.

Access to water resources has gained extensive scientific and political relevance over the last three decades. The French modern experience has become a reference point for the institutionalization of new management practices. In Brazil, this experience provided a basis for establishing not only new state management apparatuses, but also the Water Resources National Policy itself. This article seeks to examine relevant social disputes concerning water management technocracy over the establishing period of the new management apparatus. Thus, we have reviewed the sociopolitical net involving agents, groups, and social institutions towards the definition of a new regulatory frame. This frame has resulted in a symbolic re-designation of the resource (reaching the category of natural capital) and a 'scientification' of politics as a principle for legitimating competence in water governance.

\section{SOCIOLOGIE DE LA GOUVER- NANCE FRANÇAISE DES EAUX}

\author{
Rodrigo Constante Martins
}

Mots-clés: Société et ressources en eau; Bureaucratie et gestion environnementale; Régulation environnementale; Gestion des eaux.

Au cours des trente dernières années, le sujet de l'accès aux ressources en eau a conquis un espace important aussi bien dans le domaine scientifique que politique. L'expérience française moderne s'est révélée une référence importante pour l'institutionnalisation des nouvelles pratiques de gestion. Au Brésil, cette expérience est à la base non seulement de la constitution de nouvelles entités gestionnaires au niveau des États de la fédération, mais aussi de la Politique Nationale des Ressources en Eau. L'objectif de cet article est de présenter une interprétation sociologique relative à la constitution de l'actuel modèle français de gouvernance des eaux. L'auteur tente de reconstituer les enjeux sociaux les plus pertinents impliqués au sein de la technocratie de l'administration des eaux, au moment de la formulation du nouveau système de gestion. Pour cela, il reconstitue la trame sociopolitique qui a intégré des agents, des groupes et des institutions sociales dans la définition des nouvelles limites de la régulation. 